\title{
KEBUTUHAN AIR KELAPA SAWIT DAN DOMESTIK PADA WILAYAH PERKEBUNAN KELAPA SAWIT BINTURUNG ESTATE KECAMATAN PAMUKAN UTARA KALIMANTAN SELATAN
}

\author{
NOVRIANTI VERANICA \\ Dosen Pada Fakultas Teknik Universitas Muhammadiyah Palangkaraya
}

\begin{abstract}
Less than optimal use of water management in oil palm plantations "Binturung Estate" as a result of lack of maintenance of the water system konfisi. Increased water demand with increasing population and water demand on palm oil plants, less frequentlymet during the dry seasonis long enough. To meetthe needs of a need to work with to make ponds and calculate the volume of water that can be accommodated.

From the calculation of the volume of water that can be accommodated for an area of $42,000 \mathrm{~km}^{2}$, storage ponds for $0,0360 \mathrm{~m}^{3} / \mathrm{sec}>$ volume of water need sof $0.00057 \mathrm{~m}^{3} / \mathrm{s}$.
\end{abstract}

Keywords: Binturung Estate, water needs, volume the shelter

\section{ABSTRAK}

Kurang optimalnya penggunaan tata air pada perkebunan kelapa sawit "Binturung Estate" sebagai akibat kurang terpeliharanya kondisi tata air. Kebutuhan air yang meningkat dengan bertambahnya penduduk serta kebutuhan air bagi tanaman kelapa sawit, sering kurang terpenuhi pada waktu musim kemarau yang cukup panjang.

Untuk mencukupi kebutuhan air perlunya adanya kerja dengan membuat kolam penampungan dan menghitung volume air yang dapat ditampung.

Dari perhitungan volume air yang dapat ditampung untuk luas wilayah $42.000 \mathrm{~km}^{2}$, kolam penampung sebesar $0,02360 \mathrm{~m}^{3} /$ det $>$ volume kebutuhan air sebesar $0,00057 \mathrm{~m}^{3} /$ det.

Kata kunci : Binturung Estate, kebutuhan air, volume kolam penampungan

\section{PENDAHULUAN}

Kelapa sawit sangat penting artinya Bagi Indonesia dalam kurun waktu 20 tahun terakhir ini sebagai komoditi andalan untuk ekspor maupun komoditi yang diharapkan dapat meningkatkan pendapatan dan harkat petani perkebunan serta transmigrasi Indonesia.

Potensi lahan di provinsi Kalimantan Selatan terdapat Kab. Kota Baru ( Kec. Batu Licin seluas 4300 ha, Kec. Pudi, Gunung Batu Besar seluas 7.000 ha, Kec. Bakan, Sungai Durian seluas 29.620 ha, dan Kabupaten Palangan Kecamatan Awaian Halang seluas 7.854 ha).
Kecamatan Pamukan Utara terletak antara $2^{\circ} 2^{\prime}$ Lintang Selatan sampai $2^{\circ} 25^{\prime}$ Lintang Selatan dan $116^{\circ} 15^{\prime}$ Bujur Timur sampai $116^{\circ} 33^{\prime}$ Bujur Timur Kabupaten Kota Baru. Secara administratif, batas-batas wilayah adalah sebagai berikut:

a) Utara : Provinsi Kalimantan Timur
b) Selatan : Kecamatan Sungai Durian
c) Barat : Kecamatan Pamukan Barat
d) Timur : Selat Makasar
Sungai Binturung terletak di daerah Binturung Estate, terdiri dari anak sungai Cergai. Binturung Estate memiliki luas 4200 hgu (hak guna usaha) terdiri dari 4 divisi : divisi 1 , divisi 2 , 
divisi 3, dan divisi 4. Pada waktu musim hujan sering mengalami banjir hingga menggenangi lahan kebun dan jalan utama di divisi II, III dan IV yang topografinya lebih rendah sehingga banjir dapat mencapai 1-1,5 m, sedangkan pada waktu kemarau cukup panjang akan mengalami kekeringan dan air menjadi payau serta kolamkolam buatan atau waduk sebagai penampung air hujan pada setiap divisi pun menjadi kering. Kolam-kolam atau waduk dibuat untuk keperluan pembibitan dan keperluan karyawan serta penduduk sekitar unruk kehidupan sehari-hari.

Kebutuhan air sangatlah penting bagi kehidupan, terutama untuk keperluan domestik (kehidupan sehari-hari) Maupun untuk perkebuna kelapa sawit itu sendiri.

Untuk itu perlunya diadakan suatu kajian mengenai kebutuhan air bagi kelapa sawit dan domestik, sehingga diketahui berapa ketersediaan air dan berapa kebutuhan air di daerah tersebut.

\section{Perumusan Masalah}

Kolam-kolam penampugan sangat diperlukan dalam memenuhi kebutuhan air pada saat musim kering. Pengelolaan air secara terpadu dilakukan dengan menyimpan air yang berlebihan pada misim penghujan untuk dapat didistribusikan kepermukaan terutama musim kemarau. Berdasarkan har tersebut permasalahan yang akan dibahas adalah:

1. Bagaimana kondisi Eksisting daerah "Binturung Estate" ?

2. Bagaimana mencukupi kebutuhan air pada musim kemarau?

\section{Tujuan Penelitian}

1. Mengetahui kondisi Eksisting saluran primer di daerah "Binturung Estate"
2. Mengkaji sistem hidrologi di daerah "Binturung Estate"

3. Merancang kolam-kolam penampungan di daerah "Binturung Estate".

\section{Batasan Masalah}

Studi \& analisis yang digunakan dibatasi untuk permasalahan pada:

1. Sistem hidrologi pada kawasan "Binturung Estate"

2. Berdasarkan masalah ini maka akn dibuat kolam-kolam pada kawasan perkebunan desa/kelurahan "Binturung Estate" Kecamatan Pemukan Utara Kab. Kota Baru.

\section{Manfaat Penelitian}

Manfaat dari penelitian ini adalah:

1. Memberikan gambaran tentang hubungan sistem tata air dalam mendukung produksivitas kelapa sawit.

2. Membuat sarana untuk dapat digunakan untuk kebutuhan air domestik.

3. Memberikan informasi pada pihak perusahaan dan pemerintah tentang hasil dari penelitian yang dikaji agar dapat mengatasi kekeringa dimusim kemarau di kawasa "Binturung Estate".

\section{KAJIAN PUSTAKA}

Ketersediaan air merupakan salah satu factor pembatas utama bagi produksi kelapa sawit. Kekeringan menyebabkan penurunan laju fotosintetis dan distribusi asimilat terganggu, berdampak negatif pada pertumbuhan tanaman baik face vegetatif maupun face generatif. Pada face vegetatif kekeringan pada tanaman kelapa sawit ditandai oleh daun tombak tidak membuka dan terhambatnya pertumbuahan pelepah. Pada keadaan yang lebih parah kekurang air menyebabkan kerusakan jaringa tanaman yang 
dicerminkan oleh daun pucuk dan pelaepah yang mudah patah. Pada face generatif kekeringan menyebabkan penurunan produksi tanaman akibat bertambahnya pembentukan bunga, meningkatnya jumlah bunga jantan, pembuahan terganggu, gugur buah muda, bentuk buah kecil dan rendeman minyak buah rendah (Balitklimat, Litbang 2007).

Hasil penelitian di Sumatera Selatan menunjukkan bahwa secara umum kelapa sawit pada lahan pasng surut dengan jenis tanah sulfat masam masih dapat dilakukan, memperhatikan beberapa aspek, yaitu: (1) kedalaman lapisan pirit harus lebih dalam atau $70 \mathrm{~cm}$ dari permukaan tanah ; (2) pembangunan sistem tata air yang efektif untuk mencukupi oksidasi pirit sekaligus menyediakan ruang yang cukup untuk perakaran, yaitu dengan melihat ketinggian air pada level sekitar $\quad 70 \mathrm{~cm}$ dari permukaan tanah (pusat penelitian kealapa sawit, 2007).

Terkonsentrasinya curah hujan yang tinggi pada waktu yagn singkat (>250 mm selama tiga hari berturut-turut) pada awalnya akan menyebabkan tanah dan tanaman (intersepsi) menjadi jenuh, sehingga air hujan berikutnya sebagian besar airnya akan ditranfer menjasi aliran permukaan dan hanya sebagian kecil (5$10 \%$ ) saja yang disimpan dalam tanah (Iriantu, 2001).

\section{Aspek Hidrologi}

\section{Melengkapi Data Curah Hujan Yang Hilang}

Dalam melengkapi data hujan kita dapat menggunakan data hujan dari tiga tempat pengamatan. Bila selisih antara hujan-hujan tahunan total dari tempat pengamatan yang datanya tidak lengkap tersebut kurang dari $10 \%$ maka perkiraan data yang diambil dari rata-rata hitung (Arimatic mean) data tempat pengamatan yang mengelilinginya. (Imam Subarkah, 1978).

Bila selisih dapat dipergunakan metode Rasional Normal (Imam Subarkah, 1978).

\section{Analisa Curah Hujan Rerata Daerah}

Salah satu cara pendekatan untuk menentukan curah hujan rata-rata pada suatu daerah aliran sungai adalah dengan menggunakan metode Thiessen (Suyono Sosrodarsono, 1977).

\section{Analisa Distribusi Frekuensi Data Curah Hujan}

Dalam melakukan analisis distribusi frekuensi data curah hujan dilakukan dengan 2 metode yaitu distribusi Normal, Log Pearson Type III.

\section{Distribusi Normal}

Persamaan metode distribusi Normal (Sri Harto $\mathrm{Br}, 1993)$ adalah:

$$
\mathrm{X}_{\mathrm{Tr}}=\overline{\mathrm{X}}+\mathrm{K}_{\mathrm{Tr}} \cdot \mathrm{S}_{\mathrm{X}}
$$

Dengan :

$\mathrm{X}_{\mathrm{Tr}} \quad$ = Besarnya curah hujan rencana untuk periode ulang $T$ tahunan

$\overline{\mathrm{X}} \quad=$ Harga rata-rata dari data $=\frac{\Sigma_{1}^{n} X_{i}}{n}$

Sx = Simpangan baku

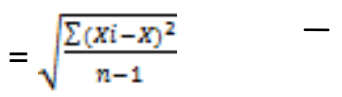

$\mathrm{K}_{\mathrm{Tr}} \quad=$ Variabel reduksi gauss

\section{Distribusi Log Pearson Type III}

Persamaan metode distribusi Log Pearson Type III (Sri Harto $\mathrm{Br}, 1993)$ adalah:

$$
\log X_{T r}=\overline{\log X}+K_{T r} \cdot(\operatorname{SLog} X)
$$

Dengan:

Log $X_{T r}=$ Besarnya curah hujan rencana untuk periode ulang $T$ tahun

$\overline{\log X} \quad=$ Harga rata-rata dari data $\frac{\sum_{1}^{n} \log X_{i}}{r}$

SLogX = Simpangan baku 


$$
=\sqrt{\frac{\sum(\log x i-\log X)^{3}}{n-1}}
$$

$\mathrm{K}_{\mathrm{Tr}}=$ Koef. Frekuensi, didapat berdasarkan hubungan nilai $\mathrm{Cs}$ dengan periode ulang T tahun

$$
\text { Cs } \quad=\frac{n \sum_{i=1}^{n} \overline{(\log X i-\log X)^{3}}}{(n-1)(n-1)(\log )^{3}}
$$

\section{Pengujian Kesesuaian Distribusi Frekuensi}

Dalam penelitian ini dilakukan uji Chi-kwadrat. Uji ini dugunakan untuk menguji simpangan tegak lurus yang ditentukan dengan rumus Shahin (Soewarno, 1995) :

$$
\left(\mathrm{X}^{2}\right) \text { hit }=\sum_{i=1}^{k}\left(\frac{E F-O F}{E F}\right)^{2}, \mathrm{EF} \frac{n}{k}
$$

Dengan:

$\left(X^{2}\right)$ hit $=$ Uji statistic

OF = Nilai yang diamati (Observasi frekuensi)

$\mathrm{EF} \quad=$ Nilai yang diharapkan (Expected Frequency)

\section{Analisa Debit Rencana Dari Data Curah Hujan}

Metode yang digunakan dalam penelitian ini adalah metode Rasional Jepang dalam hal ini besarnya debit tersebut merupakan fungsi dari luas DAS, intensitas hujan, keadaan permukaan tanah yang dinyatakan dalam koefisien limpasan dan kemiringan sungai (Joesron Loebis, 1992). Debit dirumuskan:

$$
Q=0,278 \text {. C.I.A }
$$

\section{Dimana:}

$$
\begin{aligned}
Q= & \text { Debit Puncak }\left(\mathrm{m}^{3} / \text { det }\right) \\
\mathrm{C}= & \text { Koef. Limpasan } \\
\mathrm{I}= & \text { Intensitas hujan dengan durasi sama } \\
& \text { dengan waktu konsentrasi banjir } \\
& (\mathrm{mm} / \mathrm{jam}) \\
\mathrm{A}= & \text { Luas daerah aliran sungai }
\end{aligned}
$$

\section{METODE PENELITIAN}

\section{Rancangan Penelitian}

Rancangan penelitian ini dapat dilihat pada Gambar 1. berikut:

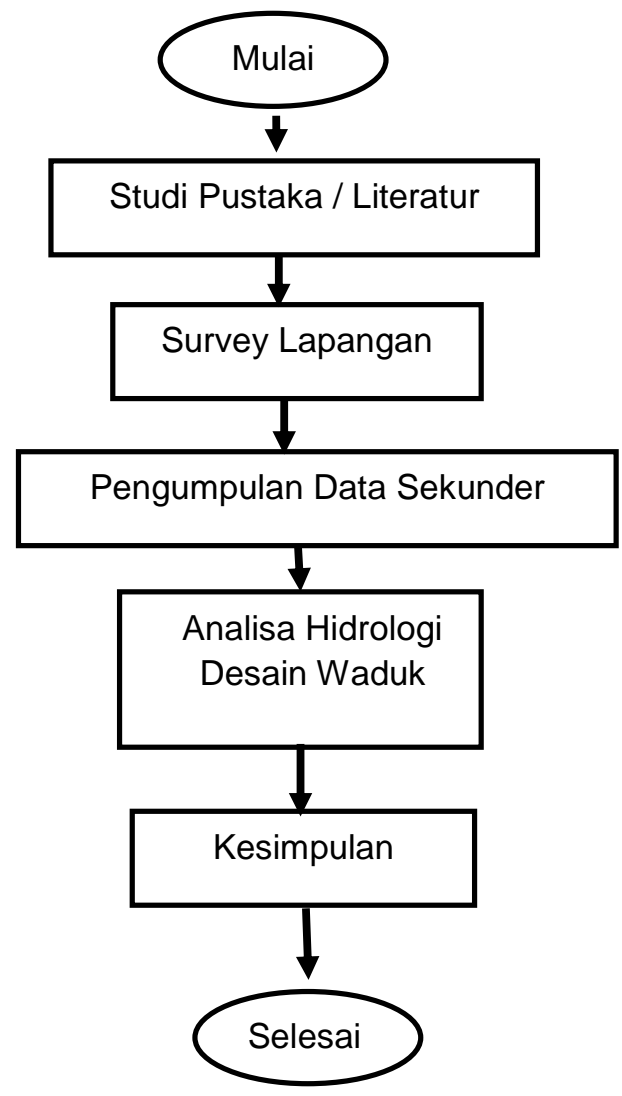

Gambar 1. Bagan Alir Penelitian

\section{Populasi dan Sampel}

Studi pustaka/criteria dilakukan dengan mengumpulkan, membaca dan mempelajari sumber pustaka baik jurnal, proseding maupun buku yang diperlukan untuk melakukan penelitian ini.

\section{Pengumpulan Data Sekunder}

Data-data sekunder yang akan digunakan dalam analisis didapatkan dari PT. Paripurna Swakarsa dan instansi pemerintah maupun lembaga lainnya. Data yang diperlukan antara lain 
1. Data kondisi lokasi studi

2. Data topografi

3. Data curahhujan

4. Data klimatologi

\section{Teknik Analisis Data}

Adapun analisis data yang dilakukan antara lain, meliputi :

1. Analisis Hidrologi

Dari data curah hujan dalam setahun dicari curah efektif tahunnya kemudian dijadikan curah hujan merata daerah dengan menggunakan metode thiessen. Data tersebut seterusnya dianalisis distribusi frekuensi data curah hujannya menggunakan distribusi normal dan log pearson. Kemudian dilanjutkan dengan melakukanan alisis debit rancangan dari data curah hujan dengan metode rasional jepang.

2. Analisis Hidrolika

Memuat kebutuhan air domestik dan kelapa sawit serta mendesain waduk untuk wilayah perkebunan.

\section{HASIL DAN PEMBAHASAN}

\section{Analisis Hidrologi \\ Data Curah Hujan}

Data curah hujan yang diperoleh dari alat penakar hujan yang terjadi pada satu tempat atau titik saja (Poin rainfall). Data curah hujan yang digunakan selama 13 tahun yang diperoleh dari pos hujan binturung estate.

\section{Analisis Distribusi Frekuensi Data Curah Hujan}

Metode yang digunakan adalah analisis distribusi normal dan distribusi log pearson type III. Dari hasil perhitungan didapat hasil analisa hujan rancangan yang dapat dilihat pada tabel 1.
Tabel 1. Hasil analisa hujan rancangan

\begin{tabular}{|l|c|c|c|}
\hline \multirow{2}{*}{ No } & \multicolumn{3}{|c|}{ Distribusi Frekuensi } \\
\cline { 2 - 4 } & $\begin{array}{c}\text { Periode } \\
\text { ulang } \\
\text { (Tahun) }\end{array}$ & $\begin{array}{c}\text { Normal } \\
\text { (mm) }\end{array}$ & $\begin{array}{c}\text { Log } \\
\text { Pearson } \\
\text { Type III }\end{array}$ \\
\hline 1. & 2 & 222,141 & 211,844 \\
\hline 2. & 5 & 280,635 & 301,227 \\
\hline 3. & 10 & 311,274 & 360,499 \\
\hline 4. & 20 & 336,343 & 408,811 \\
\hline
\end{tabular}

Sumber : Hasil Perhitungan

Untuk perhitungan selanjutnya dipakai hujan rancangan dengan periode ulang 5 tahun, untuk menampung debit puncak. Dari hasil analisa hujan rancangan untuk periode ulang 5 tahun didapat hujan maksimum adalah distribusi log pearson type III adalah $301.227 \mathrm{~mm}$ dan hujan minimum adalah distribusi normal adalah $280.635 \mathrm{~mm}$.

\section{Pengujian Distribusi Frekuensi}

Dari hasil perhitungan uji chi kuadrat didapatkan untuk distribusi normal dan log pearson type III dapat diterima dengan nilai chi kritis $=5,991$ dan nilai distribusi $x^{2}<$ chi kritis.

\section{Debit Aliran Rencana}

Dari hasil analisa dengan menggunakan metode rasional jepang maka didapatkan hasil analisa untuk periode ulang 5 tahun adalah untuk wilayah A

$$
\begin{aligned}
\text { Qp } & =0,278 \text { C. } 1 \mathrm{~A} \\
& =0,2778 \times 0,75 \times 2,92 \times 2,51 \\
& =1,53\left(\mathrm{~m}^{3} / \text { det }\right)
\end{aligned}
$$

Dan dari hasil perhitungan untuk debit total periode ulang 5 tahun adalah $32,53 \mathrm{~m}^{3} / \mathrm{det}$

\section{Analisa Evapotraspirasi (ETo)}

Dari hasil perhitungan evapotranspirasi didapat evapotranspirasi maksimum terjadi di bulan maret sebesar $161,39 \mathrm{~mm} /$ hari sedangkan evaportranspirasi minimum terjadi dibulan juni $118,06 \mathrm{~mm} /$ hari. 


\section{Kebutuhan Air}

\section{Kebutuhan Air Kelapa Sawit}

Kebutuhan air didaerah penelitian adalah $272 \times$ 4200 ha $=1.142 .400$ liter/hari.

\section{Kebutuhan Air Domestik}

Kebutuhan air domestic dalam satu tahun adalah : $82,5 \times 600$ orang $=49.500$ liter $/$ hari. Dari perhitungan kebutuhan air setiap harinya untuk kelapa sawit dan domestik sebesar $=1.191 .900$ liter/hari atau sebesar $1.191 .9 \mathrm{~m}^{3} /$ detik

\section{Water Balance}

Dari hasil perhitungan debit banjir maksimum dengan metode rasional di dapat $32,53 \mathrm{~m}^{3} /$ det dan kebutuhan air domestik $49,5 \mathrm{~m}^{3} /$ hari atau $=$ $0,00057 \mathrm{~m}^{3} /$ det, sehingga memerlukan tempat untuk menyiapkan air $>0,00057 \mathrm{~m}^{3} /$ det. Bila keperluan air selama 3 bulan waktu musim kemarau maka $49,5 \mathrm{~m}^{3} /$ hari $\times 90$ hari $=4.455 \mathrm{~m}^{3}$

\section{Kolam Penampungan}

Berdasarkan hasil perhitungan volume air yang dapat ditampung untuk luas $42.000 \mathrm{~km}^{2}$ dibuat kolam penampungan sebesar $0,02360 \mathrm{~m}^{3} /$ det > volume kebutuhan air sebesar $0,00057 \mathrm{~m}^{3} /$ det.

\section{KESIMPULAN DAN SARAN}

\section{Kesimpulan}

1. Berdasarkan analisis hidrologi bahwa daerah penelitian curah hujan yang ada cukup tinggi, dengan hasil uji chi-kuadrat dapat diterima. Berdasarkan hasil perhitungan debit rasional periode ulang 5 tahun adalah $32,533 \mathrm{~m}^{3} /$ det.

2. Berdasarkan hasil perhitungan kebutuhan air, dapat :

a. Kebutuhan air kelapa sawit sebesar 1.142 .400 liter/hari b. Kebutuhan air domestik sebesar 49.500 liter/hari Total kebutuhan domestic selama 3 bulan pada waktu mesin kemarau diperlukan tempat penyimpanan air $>4.455 \mathrm{~m}^{3}$

\section{Saran}

Dari hasil penelitian diberikan saran sebagai berikut :

1. Perlunya kolam penampungan sebagai tempat penampungan dan dapat dipergunakan untuk keperluan tanaman maupun keperluan domestik sehari-hari serta menampung luapan hujan dimusim hujan

2. Perlu adanya Kajian lanjutan untuk menentukan dimensi saluran primer dan konstruksi kolam dengan rinci dan mengidentifikasi masalah banjir yang terjadi pada kawasan perkebunan "Binturung Estate"

\section{DAFTAR PUSTAKA}

Balitlimat, Litbang, Deptan. 2007. Pengelolaan Air untuk Peningkatan Ketersediaan Air Tanaman kelapaSawit di PTPN VIII Cimulang.

Irianto, et al, 2001. Peranan Hidroklimatologi dalam mendukung pengembangan lahan kering di Indonesia. Peranan Agroklimat Dalam mendukung Pengembangan Usaha Tani lahan Kering Puslitbangtanak. Badanlitbang Departemen Pertanian

Loebis, Joesron, 1992. Banjir Rencana Untuk Bangunan Air. Dunia Grafika Indonesia. Jakarta.

Soewarno. 1995. Hidrologi Teknik Sipil

Sosrodarsono, Suyono, 1977. Hidrologi Pengairan 